\title{
The impact of the South African energy crisis on emissions
}

\author{
I. Pretorius, S. J. Piketh \& R. P. Burger \\ Eskom Engineering Power Plant Institute - Emission Control, \\ Climatology Research Group, Unit for Environmental Sciences and \\ Management, North-West University, South Africa
}

\begin{abstract}
Worldwide the energy sector has a major environmental impact. Recent decades have seen exponential growth in population and therefore also in energy demand and environmental concerns. Many countries in the world are currently facing energy shortages, including major developing countries such as China and India. This paper evaluates the link between an energy restricted environment and emissions in South Africa, a country plagued by energy shortages since the middle 2000s. Lessons learned from the South African energy crisis hold important implications for countries facing similar challenges or those whose energy reserves are kept low in order to produce energy at competitive prices. It was found that the South African energy crisis had an undeniably negative impact on emissions. Emissions from large power stations increased due to lowered maintenance and deterioration of the stations. The removal efficiencies of emissions abatement technologies decreased due to the increased pressure on these systems and missed maintenance opportunity. The South African electricity tariff increased dramatically. In combination with weak economic growth (partly due to the energy shortages in the country) and the unreliability of electricity supply, poor households are expected to increasingly make use of solid fuel burning in order to meet their energy and heating demands. Higher income households and businesses, on the other hand, make use of diesel-fuelled back-up generators during times of electricity load shedding.

Keywords: energy crisis, emissions, coal, domestic burning, developing country.
\end{abstract}




\section{Introduction}

Since the middle 2000s, South Africa experienced energy shortages. The energy shortages led to blackouts across the country and hence the term 'the South African energy crisis' was born. The reasons for the energy crisis are three-fold. A dramatic increase in demand was experienced after 1994 when the economic sanctions of the apartheid era were lifted and rapid industrialization took place [1]. The free basic energy policy was implemented in 2001 where $50 \mathrm{MWh}$ of electricity was supplied to poor households free of charge. This was done as part of a drive to provide basic services to previously disadvantaged households [1]. In 2004 the government delayed making a decision to fund the building a new power station, when it became apparent that new energy capacity was needed [1].

Approximately $85 \%$ of South African energy is generated by large coal-fired power stations. Eskom, the public energy utility, is responsible for generating $95 \%$ of South African energy. The remaining 5\% of energy is generated by privately owned and municipal energy installations [2].

Since the onset of the energy crisis, energy demand was met by means of delaying maintenance on the generation fleet. This 'keeping the lights on' strategy led to the decline in performance of the fleet, which negatively impacted the effectiveness of the fleet to meet future demand [3]. Three older, less efficient, power stations that were decommissioned during the 1980s and early 1990s returned back to service to alleviate the pressure on existing stations. Diesel-fired Open Cycle Gas Turbines (OCGT) was increasingly used, producing energy at exuberant costs. It is believed that the energy demand/supply balance will remain vulnerable until Medupi, a new power station currently under construction, comes fully online expectedly in 2018 (although uncertainty exists around the precise date).

The aim of this paper is to investigate the effect the South African energy crisis had (and still has) on emissions. Direct impacts of the energy crisis on emissions includes those associated with the decline in thermal efficiency of the coal fired power station fleet, due to the increased pressure on the fleet, reduced maintenance and the return to service of older, less efficient stations. Increased emissions can also be expected from the increased use of diesel fuelled OCGT's. Indirect impacts on emissions include the effect the energy crisis had on the use of solid fuel burning by poor households due to the increased price of electricity, the unreliability of electricity and the low economic growth and the use of back-up generators by higher income households and business during electricity load shedding.

\section{The energy crisis}

The energy crisis is characterised by a reduction in electricity reserve. Electricity reserve is the amount of reserve energy in an electric power system left after consumer supply has been met at all times. The electricity reserve is needed to operate reliably in the face of unplanned events, such as equipment outages, planned and unplanned maintenance and fluctuations in demand due to 
occurrences such as unusually cold weather conditions [4, 5]. Electricity reserve can therefore be used as an indicator of how much pressure an electricity generation system experiences. When energy demand is greater than supply there will be very little spare energy in the system [4].

The decline in the reserve of the South African energy system during the energy crisis years (2007 onwards) is illustrated in Figure 1 [2, 4, 6-12].

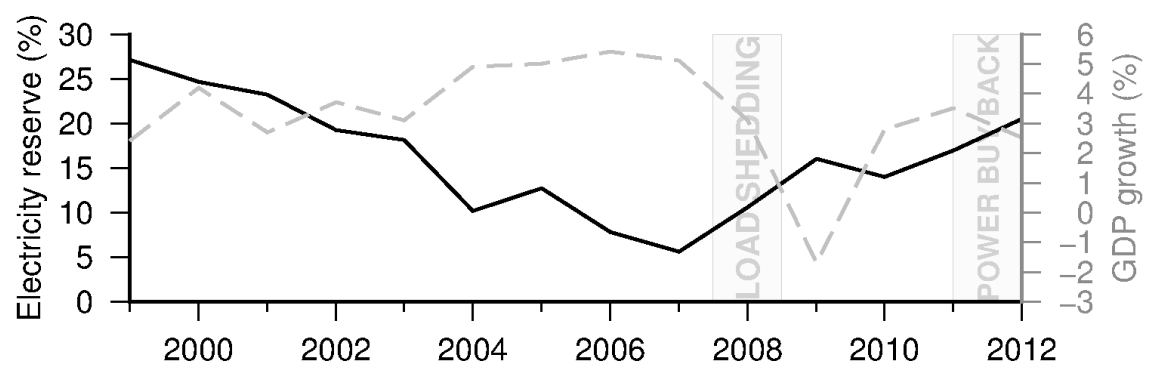

Figure 1: The electricity reserve (\%) of the South African coal fired power station fleet and the real annual percentage growth rate of the South African GDP during the period 1999 to 2012 [4].

During the period leading up to the energy crisis and during the energy crisis itself, the electricity reserve fell well below the South African aspiration of 15\%. Internationally, electricity reserve requirements usually fall in the range of $15 \%$ to $25 \%[4,5]$. During the end of 2007 and beginning 2008, the energy system could not keep up with demand and load shedding had to be implemented across the country for the first time. A number of load shedding cycles have followed since. It is important to note that the reserve margin for 2011 and 2012 are skewed by the application of a power buy-back program by which certain energy intensive consumers were paid not to use energy during this period. This was done in order to increase the electricity reserve and avoid power cuts. The energy crisis had a profound negative impact on the South African economy as illustrated by the negative real annual percentage growth of the South African GDP in 2007 and 2008 (Figure 1) [4, 13-16]. However, since 2008, the global economic crisis also contributed to reduced growth.

As a result of a very thin electricity reserve, scheduled maintenance of power stations was deferred in 2008. This was done amidst the increasing pressure the South African government placed on Eskom to 'keep the lights on' at all costs. This was later dubbed the 'keeping the lights on' strategy. The maintenance backlog led to increased breakdowns of plants and therefore increased plant unavailability. This is illustrated by the increase of the unplanned capability loss factor (UCLF) (a measure of the power lost due to the unplanned shutdown of power stations) after the deferral of maintenance in 2008 (Figure 2) [18]. Early 2015, Eskom and Government acknowledged that the 'keeping the lights on' strategy was unsustainable and the strategy was revoked. Eskom developed a maintenance regime in order to catch up the maintenance backlog [18]. 


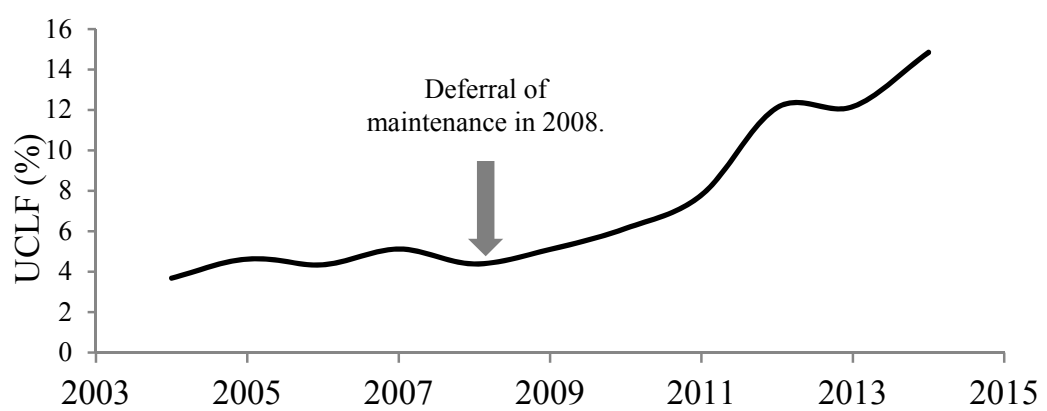

Figure 2: The Unplanned Capacity Load Factor (UCLF) (\%) for South African coal-fired power stations during the period 2004 to 2014 (Dec) [18].

\section{The impact on coal-fired power station emissions}

The deterioration in the condition of the South African coal-power station fleet and the return to service of older, less efficient power stations, led to the decrease in overall thermal efficiency of the fleet (Figure 3) [2, 6-12]. A sharp decrease in the thermal efficiency of the fleet is evident from 2009 onwards.

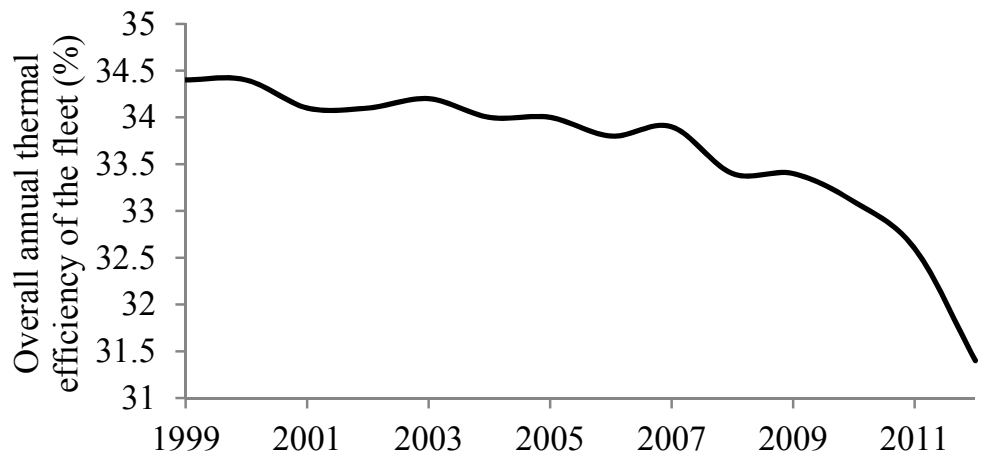

Figure 3: Overall thermal efficiency of the south African coal-fired power station fleet during the period 1999 to 2012 [2, 6-12].

The decrease in thermal efficiency of the fleet essentially means that more fuel needs to be burned in order to produce the same amount of energy output. This is illustrated in Figure 3 where total coal consumption and annual TWh energy sent out (TWhSO) by the South African coal-fired power station fleet is indicated from the period 1999 to 2012. Coal consumption and energy sent out curves follow the same trend until around 2006 where coal consumption starts to increase relative to energy sent out. During the period 2009 to 2012 coal consumption relative to energy sent out is around $10 \%$ higher than before the energy crisis. 


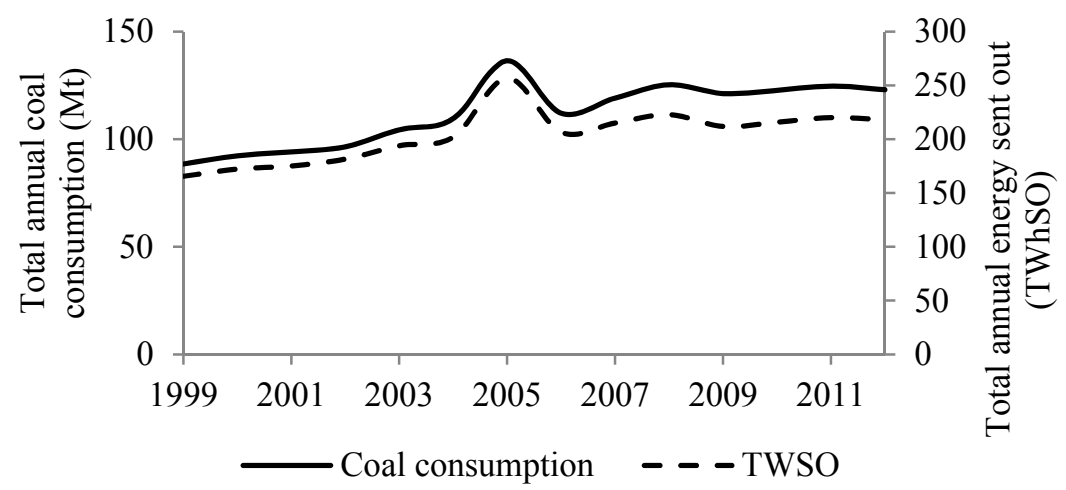

Figure 4: Coal consumption (Mt) and energy output (TWhSO) by the South African coal-fired power station fleet for the period 1999-2012 [4].

As a result of the increase in relative coal consumption per energy output by the South African coal-fired power station fleet from the onset of the energy crisis period, it is expected that (if operating conditions remain constant) emissions will at least increase by roughly the same percentage. This was true for $\mathrm{NO}_{\mathrm{x}}$ and $\mathrm{CO}_{2}$ emissions, as relative emissions of these pollutants (emissions per energy output) increased proportionally to coal consumption (Figure 5). However, this was not true for emissions of $\mathrm{SO}_{2}$ emissions (Figure 5) as average sulphur contents of fuel burned during the energy crisis period decreased.

PM emissions were the most affected by the energy crisis. The reason for this is that PM is the only pollutant currently controlled by means of abatement at coal fired-power stations in South Africa. Approximately half of South African thermal power plants make use of Electrostatic Precipitators for PM control and the other half make use of Fabric Filters. A sharp increase in relative PM emissions was experienced between 2007 and 2010 (Figure 5). Absolute PM emissions increased approximately $100 \%$ between 2007 and 2010 when energy output only increased by around $7 \%$ during the same period. This can be explained by the increase in relative PM emissions due to the increased pressure on PM abatement equipment and missed maintenance opportunity during this period. From 2010 onwards, relative PM emissions started to decline, albeit not to pre-energy crisis levels. This reduction is a result of the major modifications that were completed on particulate emission abatement equipment in 2010 [7].

\section{The impact on OCGT emissions}

During 2004 it became apparent that South Africa was heading for an energy crisis and that there was a very short lead time in order to invest in technology in order to have enough electricity to get through the winter peaks of 2007 [18]. After intensive investigations it was decided that the most viable technology was to 

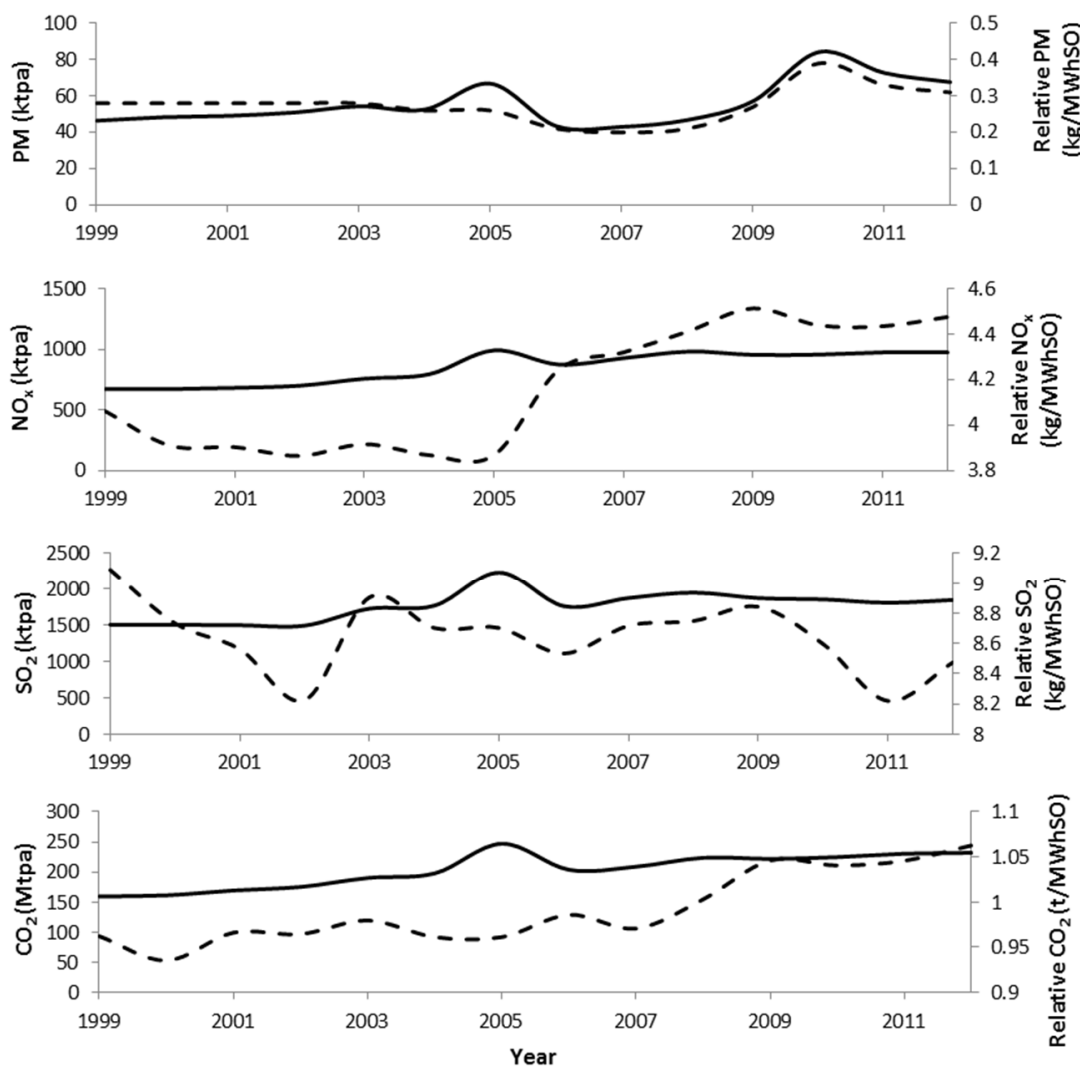

— Absolute emissions _ - - Relative emissions

Figure 5: Absolute and relative emissions of $\mathrm{PM}, \mathrm{NO}_{\mathrm{x}}, \mathrm{SO}_{2}$ and $\mathrm{CO}_{2}$ from South African coal-fired power stations during the period 1999 to 2012 [4].

invest in the building of OCGT's. Reasons for choosing this technology included the availability of the technology, the short lead times needed for installation and the proven track record of the technology [18]. Construction on two OCGT's started in 2006 and ended in 2009. These stations form part of peaking generation units and are indented to be used only at peak demand periods (mornings and evenings), however, the stations can be run up to eight hours a day should it be necessary. The cost of running OCGT's is extremely high compared to coal-fired power stations (approximately ten times higher than the cost of generating energy from coal) [19]. Diesel usage by the OCGT plants increased dramatically from 2009 to 2013, and expectedly, so did emissions (Figure 6) [18, 20, 21]. 


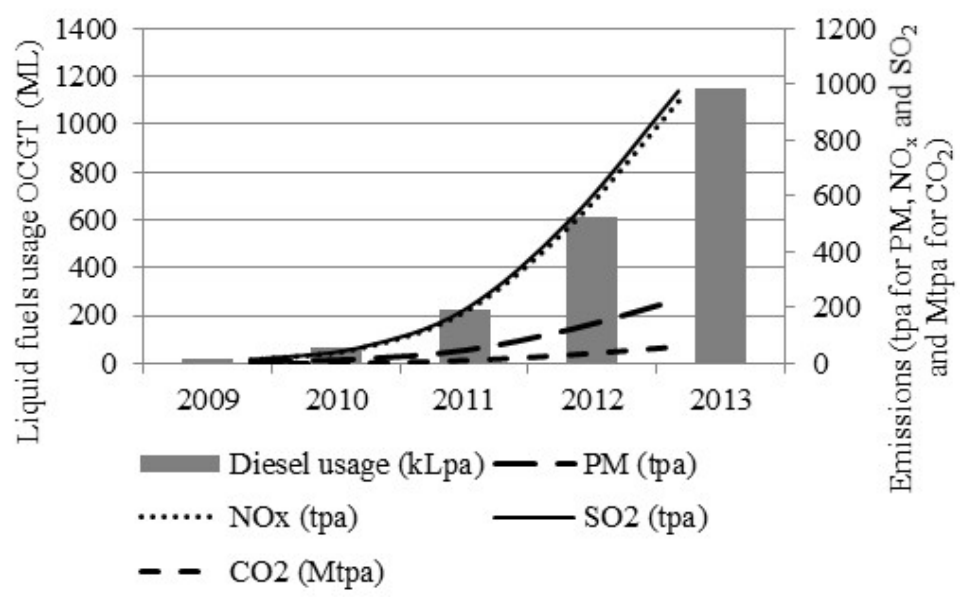

Figure 6: Fuel usage (ML) and emissions from OCGT's in South Africa for the period 2009 to 2013 [12].

\section{The impact on domestic burning emissions}

Domestic burning of wood, coal and paraffin is practiced by the very poor, living in informal settlements, in South Africa. In 2011, the number of households living in informal settlements was in the order of 1.25 million, of which $57 \%$ of these households did not have access to electricity. Of the $43 \%$ of households that did have access to electricity, many opted to still make use of domestic burning of wood, paraffin and coal for their cooking and heating needs [22].

During the period 2008 to 2011 , real electricity tariffs increased by $78 \%$ as a result of the on-going energy crisis [23]. The type of energy source used by households is strongly linked to per capita income (Figure 7) [24]. Electricity and gas usage increases with per capita income whereas candles, fuel wood and paraffin are used mostly by the poorest quintile in South Africa [24]. It can therefore be expected that when energy prices increase and economic growth is low, electricity will no longer be affordable to poor households (even if they are connected to the electricity grid) and more and more households will be forced to make use of domestic burning in order to fulfil their energy needs.

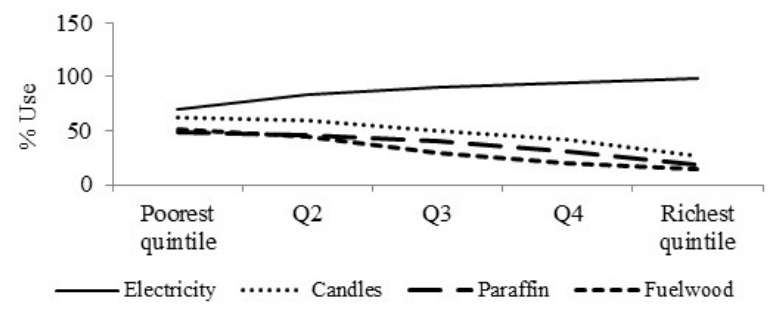

Figure 7: The use of energy sources (\%), by quintiles of per capita monthly income [24]. 
Research have found that even though a significant number of households were connected to the electricity grid from the middle 1990s to middle 2000s, the increase in the price of electricity as well as the deterioration of the electricity redistributor is slowing down progress. New connection rates cannot keep up with current household formation let alone make up for backlogs. It now seems as if the number of household without electricity is on the increase [25].

Past studies have found that of all sources of air borne emissions in South Africa, domestic burning have by far the largest impact on human health [26, 27]. The reason for this is the close proximity of emissions to humans (at ground level), the concomitance of peak emissions with periods of poor atmospheric dispersion (early morning, night time and winter time) and the release of these emissions within areas of dense population exposure to both indoor and outdoor pollution concentrations [27].

There are manifold health risks associated with domestic burning activities, which act on the respiratory system when high concentrations of PM and other pollutants are inhaled [28]. In poorly ventilated dwellings, indoor smoke can be 100 times higher than acceptable levels for PM [29]. Main health risks include pneumonia, stroke, ischaemic heart disease, chronic obstructive pulmonary disease and lung cancer. The most affected population groups are women and young children as they spend the most time near the domestic hearth [29]. When people fall ill as a result of exposure to domestic burning emissions, it impacts their ability to work as well as the country's health budget, thereby ultimately impacting negatively on the economy.

\section{The impact on small back-up generator emissions}

Numerous businesses and private households (middle and upper class) make use of small $(<440 \mathrm{~kW})$ diesel-fuelled back-up generators in the event of electricity blackouts and scheduled load shedding. It is estimated that back-up generators with a total capacity in the order of $3500 \mathrm{MW}$ is currently installed in South Africa [30]. During late 2014 and beginning 2015, load shedding has taken place, on average, approximately 12.5 days a month for two and a half hours a day throughout the country. When it is assumed that $3000 \mathrm{MW}$ of back-up generators run for two hours every time load shedding occurs over the period of a year, an estimated $1505 \mathrm{t} \mathrm{PM}, 21204 \mathrm{t} \mathrm{NO}_{\mathrm{x}}, 1402 \mathrm{t} \mathrm{SO}_{\mathrm{x}}$ and 786.6 $\mathrm{Mt} \mathrm{CO}_{2}$ is emitted [20]. As in the case of domestic burning emissions, emissions from small back-up generators occur at ground level and often in relatively dense population areas. It is estimated that load shedding will continue in South Africa, at least for another two years, until the first units of new power stations that are currently under construction come online.

\section{Conclusions}

Lessons learned from South Africa show that there is an undeniable link between energy reserve and atmospheric emissions. These lessons are applicable also to 
other countries currently facing energy shortages or to those whose energy reserve is kept low in order to produce energy at competitive prices.

Emissions from large scale coal-fired power stations increased due to decreased maintenance and the return to service of older, less efficient stations that were decommissioned. OCGT emissions increased as a result of increased usage, past their intended peak generating function. Small back-up generator emissions increased as businesses as well as middle- and upper class households utilise them to generate energy during periods of load-shedding.

The most worrying impact of the energy crisis is that of increased domestic burning. The reason for this being increased electricity tariffs, decreased economic growth and reliability of electricity provision and a decrease in the grid connection rates. Emissions resulting from the domestic burning of solid fuels and paraffin have high negative impacts on human health.

Proper planning could have prevented the energy crisis, as signs of the energy crisis approaching were apparent before the crisis struck. The famous 5 P's acronym, namely 'Proper Planning Prevents Poor Performance' can therefore perhaps be rephrased in order to create a $4 \mathrm{P}$ acronym for countries with low energy reserves: 'Proper Planning Prevents Pollution'.

\section{References}

[1] Inglesi R \& Pouris A., Forecasting electricity demand in South Africa: A critique of Eskom's projections. S Afr. J. Sci. 106(1), 2010.

[2] Eskom, Eskom Integrated Report. Eskom holdings Limited, 2012.

[3] Department of Energy, Integrated Resource Plan for Electricity 2010-2030. Update Report, 2013.

[4] Pretorius, I., Piketh, S.J., Burger, R.P. \& Neomagus, H., A perspective of South African coal fired power station emissions, J. energy South. Afr (submitted).

[5] Department of Energy, Reserve Margin - IRP 2010, Input Parameter information sheet (Supply input), 2011.

[6] Eskom, Eskom Annual Report, Eskom holdings Limited, 2006.

[7] Eskom, Eskom Annual Report, Eskom holdings Limited, 2007.

[8] Eskom, Eskom Annual Report, Eskom holdings Limited, 2008.

[9] Eskom, Eskom Annual Report, Eskom holdings Limited. 2009.

[10] Eskom, Eskom Annual Report, Eskom holdings Limited, 2010.

[11] Eskom, Eskom Integrated Report, Eskom holdings Limited, 2011.

[12] Eskom, Eskom Integrated Report, Eskom holdings Limited, 2013.

[13] Statistics South Africa, Gross Domestic Product, Fourth quarter 2008, Statistical release, Pretoria, 2009.

[14] Statistics South Africa, 2011. Gross Domestic Product, Fourth quarter 2010, Statistical release, Pretoria, 2011.

[15] Statistics South Africa, 2013. Gross Domestic Product, Fourth quarter 2012, Statistical release, Pretoria, 2013.

[16] Statistics South Africa, 2014. Gross Domestic Product, Fourth quarter 2013, Statistical release, Pretoria, 2014. 
[17] Matona, T., Eskom Chief Executive, Media Presentation, 2015.

[18] Eskom, Ankerlig and Gourikwa Gas Turbine Stations, Fact Sheet, 2014.

[19] Ndebele, P., More solar, less diesel power and coal, Engineering News, 2015.

[20] United States Environmental Protection Agency (USEPA), Stationary Point and Area Sources, Compilation of Air Pollutant Emission Factors, Fifth Ed., 1995.

[21] Australian Government, Department of Sustainability, Environment, Water, Population and Communities, Emission estimation technique manual for Fossil Fuel Electric Power Generation, National Pollutant Inventory (NPI), Version 3, 2012.

[22] Housing Development Agency, South Africa: Informal settlements Status (2013), Research Report, Johannesburg, 2013.

[23] Deloitte, The Economic Impact of Electricity Price Increases on Various Sectors of the South African Economy. A consolidated view based on the findings of existing research, 2012.

[24] Department of Energy, A survey of energy-related behaviour and perceptions in South Africa, The Residential Sector, 2012.

[25] Trollip, H., Butler, A., Burton, J., Caetano T., \& Godinho, C., Energy security in South Africa, Research paper, International Mitigation Action Plans and Scenarios, Issue 17, 2014.

[26] Friedl, A., Holm, D., John, J., Kornelius, G., Pauw, C.J., Oosthuizen, R. \& van Niekerk, A.S. Air pollution in dense, low-income settlements in South Africa. Proceedings of the National Association for Clean Air (NACA) Conference, 2008, Nelspruit, Mpumalanga, 2008.

[27] Fund for Research into Industrial Development Growth and Equity, Study to examine the potential socio-economic impact of measures to reduce air pollution from combustion, 2004.

[28] Naidoo, S., Piketh, S.J. and Curtis, C., Quantification of Emissions Generated from Domestic Burning Activities from Townships in Johannesburg, Clean Air Journal, 24(1), 2014.

[29] World Health Organisation, Household air pollution and health Fact sheet, http://www.who.int/mediacentre/factsheets/fs292/en/, Updated March 2014.

[30] Engineering News, Severely underused standby generators could mitigate power shortages - industry executive, http://www.engineeringnews.co.za/ article/severely-underutilised-standby-generators-could-mitigate-powershortages-industry-executive-2012-09-21, Published September 2012, Accessed January 2015. 